\title{
In vitro antimicrobial activity of crude extracts of some medicinal plants from Al-Baha region in Saudi Arabia
}

\author{
Saeed S. Al-Sokari ${ }^{1}$, Aly F. El Sheikha ${ }^{1,2, *}$ \\ ${ }^{1}$ Al-Baha University, Faculty of Science, Department of Biology, P. O. Box 1988, Al-Baha, Saudi Arabia \\ ${ }^{2}$ Minufiya University, Faculty of Agriculture, Department of Food Science and Technology, 32511 Shibin El Kom, Minufiya Government, \\ Egypt
}

Email address:

elsheikha_aly@yahoo.com (A. F. E. Sheikha)

\section{To cite this article:}

Saeed S. Al-Sokari, Aly F. El Sheikha. In vitro Antimicrobial Activity of Crude Extracts of Some Medicinal Plants from Al-Baha Region in Saudi Arabia. Journal of Food and Nutrition Sciences. Special Issue: Food Processing and Food Quality. Vol. 3, No. 1-2, 2015, pp. 74-78. doi: 10.11648/j.jfns.s.2015030102.24

\begin{abstract}
Medicinal plants are the wealthy source of antibacterial agents and curatives. There is an urgent need for new antimicrobial agents, so the antimicrobial activity for Ruta graveolens L. and Ficus carica Linn. Crude extracts were evaluated for its inhibitory activity against some disease causing selected microorganisms. Root extract of Ruta graveolens L gave 8 and $7 \mathrm{~mm}$ inhibition zone against Escherichia coli 254607 and Pseudomonas aeruginosa 254992 respectively. Latex of Ficus carica Linn plants showed that it is a good inhibitor for Candida albicans 254625; whereas the rest of microorganisms (Escherichia coli 254607, Proteus mirabilis 257440, Microsporium canis, Staphylococcus aureus 254996, Klebsiella pneumoniae 254656 and Staphylococcus epidermidis 254997) gave almost a similar inhibition zone around 2-3 mm. The tested crude extract from Ruta graveolens L. and Ficus carica Linn. have proved to be promising treating agents against the tested pathogenic microbes, but it needs to be concentrated and furthermore evaluated.
\end{abstract}

Keywords: Antimicrobial Activity, Medicinal Plants, Crude Extract, Ruta Graveolens, Ficus Carica, Pathogenic Microbes

\section{Introduction}

In recent times, there have been increases in antibiotic resistant strains of clinically important pathogens, which have led to the emergence of new bacterial strains that are multi-resistant (Davies \& Davies, 2010). The nonavailability and high cost of new generation antibiotics with limited effective span have resulted in increase in morbidity and mortality (Williams, 2000). Therefore, there is a need to look for substances from other sources with proven antimicrobial activity. Consequently, this has led to the search for more effective antimicrobial agents among materials of plant origin, with the aim of discovering potentially useful active ingredients that can serve as source and template for the synthesis of new antimicrobial drugs (Moreillion, Que, \& Glauser, 2005). Bryophyllum pinnatum and Kalanchoe crenata belong to the plant family Crassulaceae. They show close proximity in usage, habitat, preparation and identification. The external morphological features of Kalanchoe crenata resemble that of Bryophyllum pinnatum. An inexperienced taxonomist and even unseasoned traditional practitioner can readily confuse the two plants. This is attested to by the same local name that is being used by Yorubas in Southwest Nigeria. Some People refer to both plants as "Odundun". Ethno botanically, most often they are prepared and administered the same way. Bryophyllum pinnatum is used in ethno medicine generally for that treatment of ear-ache, cough, diarrhea, dysentery, abscesses, ulcers, insect bites, heart-troubles, epilepsy, arthritis, dysmenorrhea and whitlow (Akinsulire et al., 2007). In southern Nigeria, it is used to facilitate the dropping and healing placenta wound of newly born babies. The plant leaf is mildly exposed to heat and the juice is squeezed out and applied a poultice to the baby's placenta on daily basis. Also, the crushed leaves as well as the extracted juice are mixed with shear butter or palm oil and rubbed on abscesses or other swellings. This is also applied on ulcers, burns and on the bodies of young children when they are ill. The leaves of this plant contain bryophyllin, potassium, malate, ascorbic, malic, and citric acids. The plant is rich in both macro and micro elements, vitamins, calcium,phosphorus, ascorbic acid, inulin (Okwu \& Josiah, 2006) and other compounds like saponin, flavonoids, anthraquinones, xanthones, bryophyllin 
A and B (Iwu, 1993). On the basis of this background, in vitro antimicrobial activities of the extracts Bryophyllum pinnatum and Kalanchoe crenata from various solvents were tested against clinically important pathogens (Akinsulire et al., 2007).

Medicinal plants would be the best source to obtain a variety of drugs. About $80 \%$ of individuals from developed countries use traditional medicine, which has compounds derived from medicinal plants (Arunkumar \& Muthuselvam, 2009). Therefore, such plants should be investigated to better understand their properties, safety and efficiency (Eloff, 2004); the use of plant extracts and phytochemicals, both with known antimicrobial properties, can be of great significance in therapeutic treatments. In the last few years, a number of studies have been conducted in different countries to prove such efficiency (Santos, Hiruma-Lima, Souza Brito, \& Vilegas, 2005; Salvagnini et al., 2006; Iha et al., 2008).

The antimicrobial properties of plants have been investigated by a number of researchers worldwide, especially in Latin America. In Argentina, a research tested 122 known plants species used for therapeutic treatments (Anesini \& Perez, 1993). It was documented that among the compounds extracted from these plants, twelve inhibited the growth of Staphylococcus aureus, ten inhibited Escherichia coli, and four inhibited Aspergillus niger and also reported that the most potent compound was one extracted from Tabebuiai mpetiginosa. The antimicrobial properties of compounds obtained from Parthenum argentatum against Candida albicans, Torulopsis, Hansenula, Klebsiella pneumonia and Pseudomonas aeruginosa was detected (Martínez, Betancourt, Alonso-González, \& Jauregui, 1996).

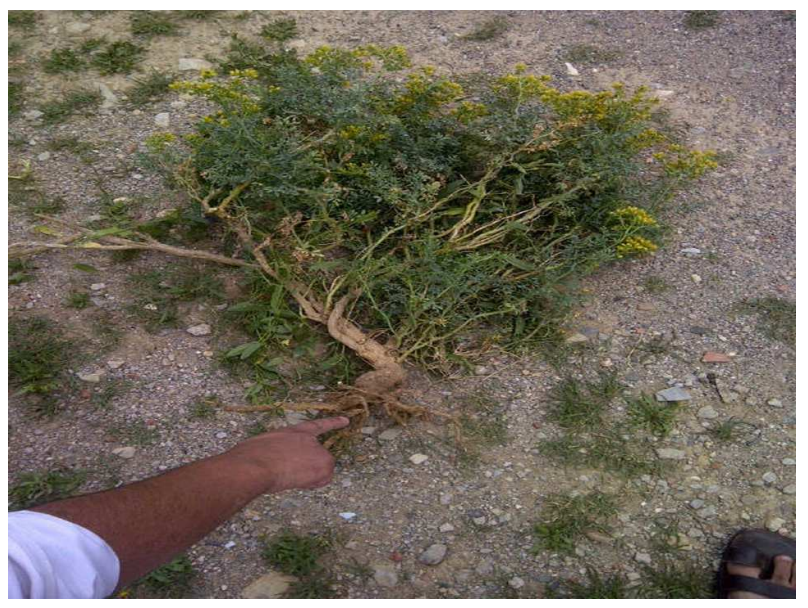

Figure 1. Ruta graveolens $L$.

Rutagraveolens L. commonly known as Rue is an herbaceous perennial, originally native to the Mediterranean region. It is now cultivated in many parts of the world. Rue has been among the key plants of the European pharmacopoeia since ancient times. Its virtues were recognized by some of the greatest Greek and Roman authors including Hippocrates, Dioscorides and Pliny (Miguel, 2003). There are two main species used in traditional medicine of which $R$. graveolens is more important (Ratheesh and Helen, 2007). It belongs to Rutaceae family in the order of Sapindales that contains about 160 genera and more than 1600 species. Due to its cultural and medicinal value, rue has been introduced in various countries of North, Central and South America, China, India, Middle East and South Africa (Miguel, 2003). $R$. graveolens has been known as "Sodaab" in Iran and distributed in northern parts of Iran especially in Gilan Province (Harat et al., 2008). R. graveolenis a small evergreen sub-shrub or semi woody perennial 0.6 to $0.9 \mathrm{~m}$ tall and almost as wide. The stems become woody near the base, but remain herbaceous nearer the tips (Fig. 1).

For a long time, $R$. graveolens has been used as a folklore medicine for treatment of various conditions such as eye problems, rheumatism, dermatitis, pain and many inflammatory diseases (Ratheesh and Helen, 2007). It was not recommended for use by pregnant or lactating women because in high concentrations it can provoke hyperemia in the uterus and high mobility (oxytocic action) which may cause abortion. At the concentrations needed for this effect, it can cause the death of a pregnant woman. $R$. graveolens is rich in rutin which act as a venotonic and capillary protector. Rutin helps increase visual sharpness and benefits other visual problems, and it was used against edema, thrombogenesis, inflammation, spasms, and hypertension (Miguel, 2003). The essential oil is spasmolytic, anti-inflammatory and antihistaminic and is a vermifuge (Mansour et al. 1989). $R$. graveolens can also be used as a rubefacient, applied in poultices for rheumatic pain, dislocations, tendon strains, varicose veins and skin conditions such as psoriasis and eczema. It has bitter eupeptic properties, so it is prescribed for stomach and intestinal disorders. If externally spread on moist skin under direct sunlight it leads to photosensitivity, caused by furanocoumarins resulting in hyper pigmentation, swelling, itching, and even burns and blistering (Miguel, 2003). A number of chemical constituents such as alkaloids, coumarins, volatile substances, terpenoids, flavonoids and furoquinolines have been isolated from different parts of the plant (Kuzovkina, Al-terman, \& Schneider, 2004).

From current pharmaceutical studies, additional pharmaceutical applications of $R$. graveolens have revealed antioxidant, anti-inflammatory (Ratheesh and Helen, 2007), antidiabetic (Toserkani, Jalali, \& Najafzaheh, 2011), antibacterial, antifungal (Meepagala, Schrader, Wedge, \& Duke, 2005), antiandrogenic (Khouri and El-Akawi, 2005), insecticide (Barbosa et al., 2011), effects among others.

Ficus carica is commonly referred as "Fig". Various parts of the plant like bark, leaves, tender shoots, fruits, seeds, and latex are medicinally important (Fig. 2).

The fig is a very nourishing food and used in industrial products. It is rich in vitamins, mineral elements, water, and fats. Figs are one of the highest plant sources of calcium and fiber. According to USDA data for the Mission variety, dried figs are richest in fiber, copper, manganese, magnesium, potassium, calcium, and vitamin $\mathrm{K}$, relative to human needs. They have smaller amounts of many other nutrients. Figs have a laxative effect and contain many antioxidants. They 
are good source of flavonoids, polyphenols and some bioactive compounds such as arabinose, $\beta$-amyrins, $\beta$ carotines, glycosides, $\beta$-setosterols and xanthotoxol. The dried figs produced a significant increase in plasma antioxidant capacity and also used in various disorders such as gastrointestinal respiratory, inflammatory, cardiovascular disorders, ulcerative diseases, and cancers. In traditional medicine the roots are used in treatment of leucoderma and ringworms and its fruits which are sweet, have antipyretic, purgative, aphrodisiac properties and have shown to be useful in inflammations and paralysis (Joseph \& Raj, 2011).

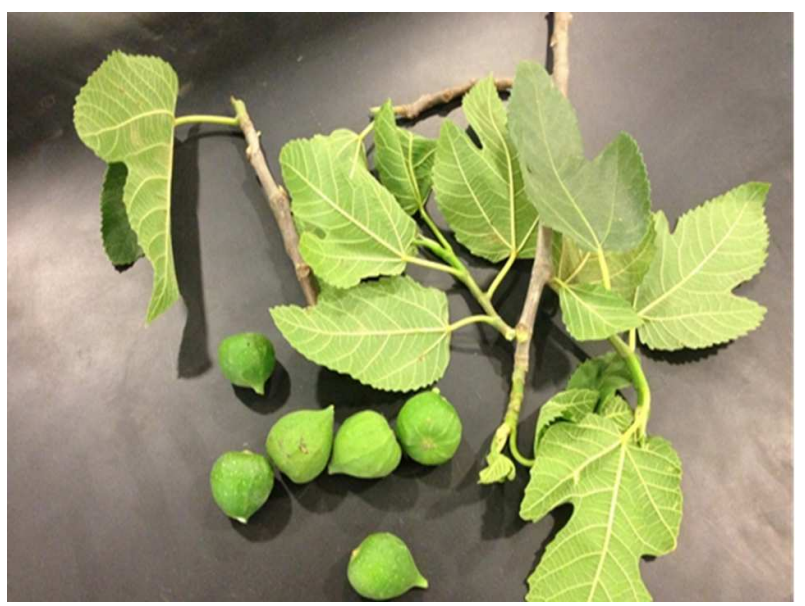

Figure 2. Ficus carica Linn.

$F$. carica has been reported to include antioxidant, antiviral, antibacterial, hypoglycemic, cancer suppressive, hypo-triglyceridaemic, and anthelmintic effects. This study was aimed to present an overview of traditional, phytochemical and pharmacological investigations of bioactive compounds present in this plant (Joseph \& Raj, 2011).

The crude extracts from Ruta graveolens L. and Ficus carica Linn. proved to be promising treating agents against the tested pathogenic microbes.

\section{Materials and Methods}

\subsection{Plant Samples}

Tested Plants were collected in the month of April 2013 from Al-Baha and were identified by taxonomist from department of Botany Department, Al-Baha University.

\subsection{Microbial Strains}

The plant extracts were assayed against following microorganisms: Pseudomonas aeruginosa 254992, Candida albicans 254625, Proteus mirabilis 257440, Escherichia coli 254607, Microsporium canis, Staphylococcus aureus 254996, Klebsiella pneumoniae 254656 and Staphylococcus epidermidis 254997, which have been stored in "Blood Bank in Al-Baha).

\subsection{Extraction Procedure of Plant Materials}

Fresh roots of $R$. graveolens $(1.4 \mathrm{~kg})$ were homogenized with EtoAc (4 L) in a commercial blender at ambient temperature and extracted twice for $12 \mathrm{~h}$ with EtoAc $(8 \mathrm{~L})$. Following filtration through filter paper (Whatman \#1), the combined EtoAc extract was concentrated by evaporation under reduced pressure at $40{ }^{\circ} \mathrm{C}$ to afford $23.05 \mathrm{~g}$ of brownyellow residue (Meepagala, Schrader, Wedge, \& Duke, 2005). Milky extract from Ficus caria (lectine) was collected and dissolved in methanol $(1: 1 v / v)$ and used for antimicrobial evaluation properties.

\subsection{Antimicrobial Bioassay of Crude Extracts}

The paper agar diffusion method of Rios et al. (1987) was used to determine the antimicrobial activity of all the extracts. Solution of crude extract was employed for testing. Nutrient agar was prepared and sterilized, and $20 \mathrm{~mL}$ of the medium was poured into each sterilized Petri plate. The plates were inoculated with test organism. The plates were left at room temperature for ten minutes allowing the diffusion of the extracts into agar and were incubated at $37{ }^{\circ} \mathrm{C}$ for $24 \mathrm{~h}$. They were inspected for the zones of inhibition of growth which were measured. A control experiment was carried out using same solvent of plant extract for each of the test organism. The average of three independent determinations was taken for each set of data (Antimicrobial evaluation has been carried out in Blood Bank in Al Baha).

\section{Results}

It is well known that infectious diseases particularly those involving microorganisms like bacteria and fungi causes a serious infection in tropical and subtropical countries of the world. Due to indiscriminate use of commercial antimicrobial drugs commonly used in treatment of various diseases the human pathogenic microorganisms have developed multiple drug resistance which creates enormous health problems. The problem of microbial resistance some time takes the shape of epidemic due to development of drug resistant microorganisms thus in recent year lot of attention is diverted to discover new source of natural antimicrobial agents .

The potential of higher plants as source of new antimicrobial agents represent a vast untapped source for exploration of natural antimicrobial agent in modern medicine. Although 100 of plant species have been evaluated for antimicrobial properties but majority of them have not been systematically evaluated. Therefore in recent years a lot of attention is being diverted to evaluate plant extracts as antimicrobial agent against plant pathogens.

In this current article, we have screened the antimicrobial effects of Ficus carica and Ruta graveolens L. against Pseudomonas aeruginosa 254992, Candida albicans 254625, Proteus mirabilis 257440, Escherichia coli 254607, Microsporium canis, Staphylococcus aureus 254996, Klebsiella pneumoniae 254656 and Staphylococcus epidermidis 254997. Most of these selected microorganisms cause serious diseases to human. For example Pseudomonas aeruginosa is a common bacterium that can cause disease in animals and humans. It is found in soil, water, skin flora, and 
most man-made environments throughout the world. It thrives not only in normal atmospheres, but also in hypoxic atmospheres, and has, thus, colonized many natural and artificial environments. It uses a wide range of organic material for food; in animals, the versatility enables the organism to infect damaged tissues or those with reduced immunity. The symptoms of such infections are generalized inflammation and sepsis. If such colonization occurs in critical body organs, such as the lungs, the urinary tract, and kidneys, the results can be fatal. Candida albicans cause Candidiasis. In recent years, Klebsiellae have become important pathogens in nosocomial infections. Staphylococcus aureus is a bacterium that is a member of the Firmicutes, and is frequently found in the human respiratory tract and on the skin. Although $S$. aureus is not always pathogenic, it is a common cause of skin infections (e.g. boils), respiratory disease (e.g. sinusitis), and food poisoning. Disease-associated strains often promote infections by producing potent protein toxins, and expressing cell-surface proteins that bind and inactivate antibodies.

Root extract of Ruta graveolens gave a good inhibition zone against Pseudomonas aeruginosa 254992 and Escherichia coli 254607 of 7 and $8 \mathrm{~mm}$ respectively (Table 1).

Table 1. Antimicrobial activity of Ruta graveolens L. and Ficus carica Linn. crude extracts against some microorganisms

\begin{tabular}{|c|c|c|}
\hline \multirow{3}{*}{ Microorganisms } & Ruta graveolens $\mathrm{L}$. & Ficus carica Linn. \\
\hline & \multicolumn{2}{|c|}{ Inhibition Zone (mm) } \\
\hline & Root extract & Latex extract \\
\hline \multicolumn{3}{|l|}{ Bacteria } \\
\hline Escherichia coli 254607 & 8.0 & 2.0 \\
\hline $\begin{array}{l}\text { Pseudomonas aeruginosa } \\
254992\end{array}$ & 7.0 & 3.0 \\
\hline Proteus mirabilis 257440 & 5.0 & 2.0 \\
\hline $\begin{array}{l}\text { Klebsiella pneumonia } \\
254656\end{array}$ & 3.0 & 2.0 \\
\hline $\begin{array}{l}\text { Staphylococcus aureus } \\
254996\end{array}$ & 2.0 & 2.0 \\
\hline $\begin{array}{l}\text { Staphylococcus } \\
\text { epidermidis } 254997 \\
\text { Yeast }\end{array}$ & 1.0 & 2.0 \\
\hline $\begin{array}{l}\text { Candida albicans } 254625 \\
\text { Fungi }\end{array}$ & 1.0 & 5.0 \\
\hline Microsporium canis & 6.0 & 3.0 \\
\hline
\end{tabular}

Latex of Ficus carica plants showed that it is a good inhibitor for Candida albicans 254625, whereas the rest of microorganisms gave almost a similar inhibition zone around 2-3 mm (Table 1).

\section{Discussion}

Antimicrobial activity of various preparation of Ruta graveolens L. including essential oils (Nogueira et al., 2008). Also it was found that it contains rutacridone epoxides that have antimicrobial activity against gram positive and negative bacteria.

The latex of fig fruit (Ficus carica) has been used in several traditional herbal medicine remedies, most of them aimed to treat skin viral infections such as warts (HPV) and other similar ones having viral origins as herpes, echovirus type 11 (ECV-11) and adenovirus (ADV), having also a significant toxic effect against early fourth-stage larvae of Aedes aegypti.

There are also studies on Ficus carica where it exerted different beneficial properties and was even able to inhibit the growth of Staphylococcus aureus, Staphylococcus epidermidis, Streptococcus pyogenes, Salmonella enteric,Serovar typhi and Pseudomonas aeruginosa, as well as in some extents against Enterococcus fecalis, Citobacter freundei, Echerchia coli,Pseudomonas aeruginosa and Proteus mirabilis.

\section{Conclusions}

The tested crude extract from Ruta graveolens and Ficus carica have proved to be promising treating agents against the tested pathogenic microbes, but it needs to be concentrated and furthermore evaluated. Hence, more studies pertaining to the use of plants as therapeutic agents should be emphasized, especially those related to the control of antibiotic resistant microbes.

\section{References}

[1] Akinsulire, O. R., Aibinu, I. E., Adenipekun, T., Adelowotan, T, \& Odugbemi, T. (2007). In vitro antimicrobial activity of crude extracts from plants Bryophyllum pinnatum and Kalanchoe crenata. African Journal of Traditional, Complementary and Alternative Medicines, 4, 338-344.

[2] Anesini, E., \& Perez, C. (1993). Screening of plants used in Argentine folk medicine for antimicrobial activity. Journal of Ethnopharmacology, 39, 119-128.

[3] Arunkumar, S., \& Muthuselvam, M. (2009). Analysis of phytochemical constituents and antimicrobial activities of aloevera L. against clinical pathogens. World Journal of Agricultural Sciences, 5, 572-576.

[4] Barbosa, F. S., Leite, G. L. D., Alves, S. M., Nascimento, A. F., D'Ávila, V. A., Costa, C. A. (2011). Insecticide effects of Ruta graveolens, Copaifera langsdorffii and Chenopodium ambrosioides against pests and natural enemies in commercial tomato plantation. Maringa, 33, 37-43.

[5] Davies, J, \& Davies, D. (2010). Origins and evolution of antibiotic resistance. Microbiology and Molecular Biology Reviews, 74, 417-433.

[6] Eloff, J. N. (2004). Quantifying the bioactivity of the plant extracts during screening and bioassay- guided fractionation. Phytomedicine, 11, 370-371.

[7] Harat, Z. N., Sadeghi, M. R., Sadeghipour, H. R., Kamalinejad, M., \& Eshraghian, M. R. (2008). Immobilization effect of Ruta graveolens L. on human sperm: New Hope Male Contraception. Journal of Ethnopharmacology, 115, 36-41.

[8] Iha, S. M., Migliato, K. F., Vellosa, J. C. R., Sacramento, L. V. S., Pietro, R. C. L. R., Isaac, V. L. B., Brunetti, I. L., Corrêa, M. A., \& Salgado, H. R. N. (2008). Estudo fitoquímico de goiaba (Psidiumguajava L.) com potencial antioxidante para o desenvolvimento de formulação fitocosmética. Revista Brasileira de Farmacognosia, 18, 387-393. 
[9] Iwu, M. M. (1993). Hand-book of African Medicinal Plants. Florida: CRC Press Inc.

[10] Joseph, B., \& Raj, S. J. (2011). Pharmacognostic and phytochemical properties of Ficus carica Linn - An overview. International Journal of PharmTech Research, 3, 8-12.

[11] Khouri, N. A., El-Akawi, Z. (2005). Antiandrogenic activity of Ruta graveolens L. in male Albino rats with emphasis on sexual and aggressive behavior. Neuroendocrinology Letters, $26,823-829$.

[12] Kuzovkina, I., Al-terman, I., \& Schneider, B. (2004). Specific accumulation and revised structures of acridone alkaloid glucosides in the tips of transformed roots of Rutagraveolens. Phytochemistry, 65, 1095-1100.

[13] Mansour, S., Al-Said, M., Tarique, M. A., Al-Yahya, S., Rafatullah, O., Ginnawi, T., Ageel, A. M. (1989). Studies on Ruta chalepensis, an ancient medicinal herb still used in traditional medicine. Journal of Ethnopharmacology, 28, 305-312.

[14] Martínez, M. J., Betancourt, J., Alonso-González, N., \& Jauregui, A. (1996). Screening of some Cuban medicinal plants for antimicrobial activity. Journal of Ethnopharmacology, 52, 171-174.

[15] Meepagala, K. M., Schrader, K. K., Wedge, D. E., \& Duke, S. O. (2005). Algicidal and antifungal compounds from the roots of Ruta graveolens and synthesis of their analogs. Phytochemistry, 66, 2689-2695.

[16] Miguel, E. S. (2003). Rue in traditional Spain: frequency and distribution of its medicinal and symbolic applications. Economic Botany, 57, 231-244.

[17] Moreillion, P., Que, Y. A., \& Glauser, M. P. (2005). Staphylococcus aureus (Including Staphyloccal Toxic shock). In G. L. Mandell, J. E. Bennett, \& R. Dolin (Eds.), Principles and practice of infectious diseases (pp. 2333-2339).
Pennyslyvania: Churchill livingstone.

[18] Nogueira, J. C., Diniz, M. F,, Lima, E. O. (2008). In vitro antimicrobial activity of plants in Acute Otitis Externa. Brazilian Journal of Otorhinolaryngology, 74, 118-124.

[19] Okwu, D. E., \& Josiah, C. (2006). Evaluation of the chemical composition of two Nigerian medicinal plants. African Journal of Biotechnology, 5, 257-361.

[20] Ratheesh, M., \& Helen, A. (2007). Anti-inflammatory activity of Ruta graveolens Linn on carrageenan induced paw edema in wistar male rats. African Journal of Biotechnology, 6, 1209-1211.

[21] Rios, J. L., Recio, M. C., Villar, A. (1987). Antimicrobial activity of selected plants employed in the Spanish Mediterranean area. Journal of Ethnopharmacology, 21, 139152.

[22] Salvagnini, L. E., Migliato, K. F., Isaac, V. L. B., Correa, M. A., Salgado, H. R. N., Pietro, R. C. L. R. (2006). Evaluation of efficacy of preservatives associated to Achillea millefolium L. extract against Bacillus subtilis. Brazilian Journal of Microbiology, 37, 75-77.

[23] Santos, L. C., Hiruma-Lima, C. A., Souza Brito, A. R. M.., \& Vilegas, W. (2005). Flavonoids and antiulcerogenic activity from Byrsonima crassaleaves extracts. Journal of Ethnopharmacology, 97, 1-6.

[24] Toserkani, A., Jalali, M. R., \& Najafzaheh, H. (2011). Changes of lipid profiles, glucose, and hemogram after administration of Ruta graveolens extract in diabetic rats. Comparative Clinical Pathology, 10, 1331-1333.

[25] Williams, R. (2000). Antimicrobial resistance a global threat. Essential Drug Monitor, 1, 28-29. 